solubility of partly carbonized coal. Palæobotanical studies have concentrated on fossil woods and spores, and the collection of modern conifer woods, begun in 1955, is now virtually complete. So also is the first stage of the fluidized coal carbonization programme begun in 1955 in co-operation with the University Department of Chemical Engineering, and it was anticipated that the equipment would be transferred to the Council's new pilot plant in the spring or early summer of 1957 . 'L'ests in Germany indicate that it is not possible to manufacture binderless briquettes of commercial quality from Alberta sub-bituminous coal in either extrusion-type or high-pressure ring-roll presses, but the possibility of using hot-briquetting processes is being explored in Europe.

Petroleum geochemistry is now recognized as the unifying theme in the work on petroleum, and the programme is being co-ordinated on this principle. Work continued on the porphyrin content of oil and its destruction in relation to the presence of vanadium, nickel and other trace elements. A detailed survey is being made of the occurrence of vanadium and nickel in the Pembina oil field with a view of following oil migration within the field, and the flow of Athabasca oil sand through a hopper is also being studied. Other work has been concerned with the characterization of the sulphur compounds in the oil-sands oil, and the selective oxidation of thiophenic acid sulphur by nitric acid. The hydrocarbon research programme deals with the mechanism of the uncatalysed pyrolysis of hydrocarbons and the decomposition of halo-hydrocarbons.

The work on natural gas has been reoriented, and yields of acetylene and ethylene in the range of com. mercial interest were obtained by pyrolysis of $n$-butane at about $250^{\circ} \mathrm{F}$. and atmospheric pressure, greater severity of cracking favouring the formation of acetylene. Particular emphasis is being placed on the engineering problems associated with the high heat load required for such pyrolytic reactions, and fundamental studies are being made on adsorption with reference to the use of such techniques in separating hydrocarbons.

The geological section is making excellent progress with its ground-water programme, and the surficial geology of the Hardisty-Killam-Kinsella area was mapped on a scale of one inch to one mile. A Cretaceous microfaunal study was completed in cooperation with the University of Alberta and a microfaunal research project on the Exshaw formation initiated. The clay fraction of shale samples collected across the contact of the non-marine Oldham formation and the marine Bearpaw formation is being studied by X-ray diffraction, and chemical analysis and detailed petrographic and stratigraphic studies of the Lower Cretaceous Blairmore formation of southern and central Alberta continued.

Reconnaissance oil surveys were made on 500,000 acres in the Blueberry Mountain sheet, and some 10 million acres were covered in the exploratory soil survey by helicopter from the Lesser Slave Lake to the Saskatchewan boundary. Additional data were accumulated, despite unusually heavy rainfall, in the co-operative irrigation research on solanetzic soils. The highway research programme included fundamental studies on the use of electro-osmosis to inject chemicals into soils of the texture of silts and finer, as well as on the use of chrome-lignin gels for soil stabilization and for the prevention of frost heaving in soils. Comprehensive laboratory tests were made on samples of soils taken from test-holes in areas of extensive slides which have occurred in the vicinity of the town of Peace River.

The industrial engineering services section is primarily a service group, but it undertook some investigations, including work in co-operation with the University Department of Agricultural Engineering on the utilization of butane in engines. Work in animal science included a study of the influence of the productive energy level of the ration in the reproductive performance and efficiency of turkeys, and a study of the nutritive value of rapeseed oil meal.

\section{HYDRO-ELECTRIC POWER IN THE U.S.S.R.}

$Y^{\prime} T$ is always a matter of interest to the Western world when the veil of secrecy surrounding many of the activities of the inhabitants of the U.S.S.R. is lifted a little. A report was presented to a joint meeting on May 20 of the Institutions of Civil, Electrical and Mechanical Engineers on the visit of six British engineers to the U.S.S.R. to examine the hydro-electric installations there. It is clear that their hosts spared no effort to provide these visitors with the information they desired, especially with regard to those parts of their vast territory which they were unable to visit. It is also refreshingly clear that the visitors were determined to supplement this information with the results of their own observations of the installations and factories seen. In so far as the use of electricity is a pointer to the progress of industrialization of a community, the report is of value in showing the position achieved by the U.S.S.R., and some interesting comparisons with Great Britain are possible. There is a great wealth of factual information given, which makes the report heavy reading, although correspondingly more valuable, and a fair summary of the report must also, therefore, be mainly concerned with facts.

At the present time the electricity generated in the U.S.S.R. per head of population is rather less than half the corresponding figure for Great Britain. This may be accounted for to some extent by the greater proportion of rural to urban population; but another contributory factor is the more extended use of combined steam-power stations, where the heat of combustion of the fuel is partly used to generate electricity and partly used to provide steam for industrial purposes and for space-heating. This dualpurpose type of station is more attractive economically in the U.S.S.R. than in Great Britain on account of the higher proportion of the urban population who live in large blocks of flats, and 30 per cent of the plant capacity of thermal stations is in combined stations.

The rate of growth of electricity consumption in the next five years is estimated at 45 per cent (9 per cent per annum) for Great Britain, and at 88 per cent for the U.S.S.R. If these rates of progress are maintained, the U.S.S.R. should consume more electricity per head than Great Britain by 1967. Of this total electricity generated, the proportion produced by hydro-electric power is 13.5 per cent at present but is estimated to approach 20 per cent by 1960 .

The potential hydro-electric power generation of the country is enormous, and has been estimated as 
approximately eighteen times the total consumption of electricity in the U.S.S.R. to-day. Probably only 50 per cent of this can be developed economically, but even this figure provides a comfortable margin over the country's needs for many years to come. Research work is, however, being undertaken on peaceful uses of atomic energy, and atomic power stations are planned for areas where there are no local supplies of fuel and presumably no hydro-electric supplies of power.

The development of hydro-electric supplies is always combined with plans to improve the navigability of rivers and to improve irrigation. In most schemes rivers are converted into a series of large lakes and this must entail some loss of potential power through increased evaporation. In one scheme, however, in Armenia, it is proposed to lower the level of Lake Sevan over a period of fifty years in order to reduce the loss due to evaporation. According to the original scheme, the lake was to be reduced to one-sixth of its area, but a less drastic reduction is now under consideration, coupled with the diversion of water from other watersheds to make good the power lost.

The visiting engineers were generally favourably impressed with the quality of the constructional work carried out and with the technical knowledge of the engineers in control, but they mention seeing several instances of the use of rather poor concrete, and the finish of both constructional work and machinery was not always up to the best British practice. One interesting feature was the small use made of timber shuttering, pre-fabricated permanent concrete shuttering being more generally used.

Many of the structures and earthworks are founded on permeable material and a considerable research effort is devoted to the study of soil mechanics and the strength of materials and structures. Extensive use is made of models before starting full-scale construction. Most of the hydro-electric machinery is manufactured in the U.S.S.R., but the party were only able to visit two manufacturing plants. Factory workers work forty-six hours a week in. cluding six on Saturday. Overtime is paid at time and a half for the first two hours of each day and then at double time. There are also bonus incentives.

Eighty per cent of the potential water power of the country is east of the Urals, in relatively thinly populated areas, and considerable attention has, therefore, been given to transmission problems. A $400 \mathrm{kV}$. a.c. overhead line between Kuibishev and Moscow, a distance of 500 miles, has recently been completed, and there is a proposal for an $800 \mathrm{kV}$. d.c. line between Stalingrad and the Donbas area, a distance of 250 miles. Some indication of policy in the matter of electricity consumption is afforded by the fact that the private consumer may have to pay thirty times as much for his electricity as a favoured industrial consumer.

There is an interesting appendix giving the estimated total production in 1960 showing increases above 1955 ranging from 23 per cent up to a twentyone-fold increase. Comparable British figures would have been helpful here, especially for the general consumption goods. These figures show, for example, two pairs of footwear per head of population and approximately one refrigerator, one washing machine and one motor tricycle for every 400 members of the population, as the annual production in 1960 .
The members of the visiting party were Sir John Hacking, of Merz and McLellan; Mr. A. A. Fulton, of the North of Seotland Hydro-Electric Board; Dr. S. P. Hutton, of the Department of Scientific and Industrial Research Mechanical Engineering Research Laboratory ; Dr. W. MacGregor, of George Wimpey and Co., Ltd.; Mr. R. W. Mountain, of Kennedy and Donkin; and Mr. H. West, of MetropolitanVickers Electrical Co., Ltd. A. H. M. ArnoxD

\section{FRANKLIN INSTITUTE REPORT FOR 1956}

$A$ $T$ the annual meeting of the Franklin Institute which was held on January 16 , the president, Mr. S. Wyman Rolph, gave a brief summary of the activities of the Institute during 1956. The full text of the annual report of the board of managers appears in the March number of the Journal of the Franklin Institute $(263,229$; 1957).

The report states that the year under review was a successful one, both financially and otherwise, for the Institute. The Laboratories for Research and Development, which celebrated their tenth anniver. sary in March 1956, became not only self-supporting but even accumulated a surplus, which can be used for the purchase of much-needed additional equipment. For the first time the gross value of the wide range of investigations carried out for industrial sponsors and the United States government exceeded 3 million dollars. The greatest increase in effort occurred in the field of nuclear engineering, and in November a separate Nuclear Engineering Division was established to handle this particular work. The work on air pollution, carried out by the Division of Chemistry and Physics, was expanded considerably, and a mobile laboratory for the analysis of polluted air was used to study the 'smog' problem in the Los Angeles area. A public semi-technical symposium on the subject of air pollution was held at the Institute in October during Philadelphia's 'Cleaner Air Week'. An electronic recorder for the recording of transient events in proper time sequence, which is most useful in the study of mechanical strains and in chemical kinetics, was designed and constructed by the electronics section of the Electrical Engineering Division, and a Remington-Rand 'Univac' dígital computer has been installed, which will be used by the analysis section of the Division to solve engineering problems arising from projects in various departments of the Laboratories and also will be available for data processing for other organizations.

The circulation of the Institute's Journal increased from 4,734 at the end of 1955 to 4,876 at the end of 1956. The January 1956 issue commemorated the 250th anniversary of the birth of Benjamin Franklin. The group of associate editors of the Journal was increased during the year by eight new appointments to widen the coverage in electronics, mathematics, aerodynamics, thermodynamics, solid state physics, biophysics and nuclear engineering. Commencing with the July issue, Dr. J. S. Burlew succeeded Dr. H. B. Allen as editor. This followed Dr. Allen's retirement in January from the positions of executive vice-president and secretary of the Institute, and the appointment of Dr. Burlew as executive vice-president and $\mathrm{Mr}$. H. V. Bail as secretary. In order to make the facilities of the Laboratories better known to industry, the Institute 